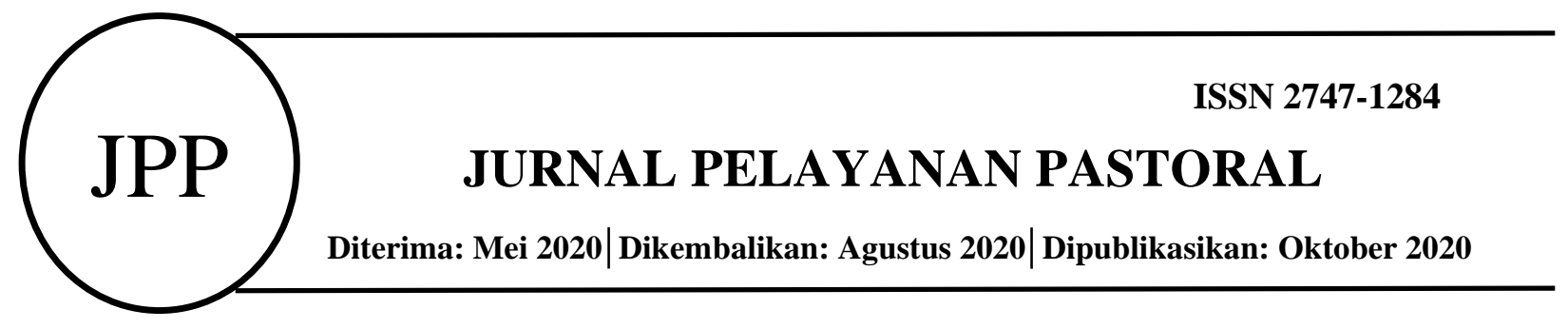

\title{
PELAKSANAAN BINA IMAN ANAK KATOLIK (BIAK) DALAM KEGIATAN WEEKEND PASTORAL
}

\author{
Yuliana Eni Yuliati*1, Maria Vianti Desa*2 \\ *12 Sekolah Tinggi Pastoral -IPI Malang \\ Jurusan Pastoral Sosial, Prodi Pelayanan Pastoral \\ e-mail: ${ }^{1}$ yulieni29@gmail.com, ${ }^{2}$ viantidesa@gmail.com
}

\begin{abstract}
Abstrak
Dalam kegiatan weekend pastoral, mahasiswa terlibat langsung dalam kehidupan iman umat, termasuk dalam kegiatan Bina Iman Anak Katolik (BIAK). Tujuan yang mau dicapai adalah mengetahui peranan petugas weekend pastoral dalam pelaksanaan katekese Bina Iman Anak Katolik (BIAK) di lingkunganlingkungan yang ada paroki santo Vincentius a Paulo Malang. Metode peneliti menggunakan pendekatan deskriptif kualitatif dengan 3 kelompok informan yaitu ketua lingkungan, pembina BIAK dan petugas weekend pastoral. Hasil penelitian ditemukan bahwa dari 9 lingkungan tempat mahasiswa melakukan kegiatan weekend pastoral ada 8 lingkungan yang memiliki kelompok kategorial BIAK dan hanya 1 lingkungan yang tidak memiliki kelompok kategorial BIAK. Semua petugas weekend berperan dalam pendampingan kelompok BIAK. Mereka mendampingi kelompok BIAK lebih kreatif dan energik, terutama dalam hal lagu-lagu. Mereka membawa persiapan sebelum mengajar, membawa sarana dan alat yang diperlukan, sehingga pelaksanaan pembinaan BIAK lebih kreatif dan menyenangkan.
\end{abstract}

Kata Kunci: Bina Iman Anak Katolik/BIAK, weekend pastoral.

\begin{abstract}
In weekend pastoral activities, students are directly involved in the life of the people of faith, including in the Catholic Children Community Development (BIAK). The goal to be achieved is to find out the role of weekend pastoral ministers in the implementation of Catholic Children Faith (BIAK) catechesis in St. Vincentius a Paulo parish, Malang. The research method used in this research is a qualitative descriptive approach with 3 groups of informants, namely the learders of communities, BIAK coaches and weekend pastoral ministers. The results showed that 8 out of 9 communities have BIAK groups and only 1 community does not have a BIAK group. All weekend pastoral ministers play roles in assisting the BIAK groups. They assist the BIAK group to be more creative and energetic, especially in terms of songs. They bring preparations before teaching, bring the necessary tools, so that the implementation of BIAK coaching is more creative and enjoyable.
\end{abstract}

Keywords: BIAK, Weekend Pastoral, catechesis 


\section{PENDAHULUAN}

Gereja adalah sakramen persekutuan atau komunio. Dasar teologis dari hal ini adalah kehidupan Allah sendiri yaitu persekutuan Tri Tunggal Mahakudus. Kehadiran Yesus di dunia adalah untuk mewartakan karya keselamatan yang ditawarkan oleh Allah sendiri untuk semua manusia. undangan Allah ini mengajak manusia untuk memiliki persekutuan dengan Allah, Sang Sumber Kehidupan.

Dengan pesekutuan dengan Allah ini, membawa dampak agar manusia memiliki persekutuan dengan sesamanya. Seperti yang ditegaskan oleh Rasul Paulus dalam 1Kor 12:27 "kamu semua adalah Tubuh Kristus dan kamu masing-masing adalah anggotanya." Karena itu, persekutuan (communio) memiliki dua aspek yaitu persekutuan dengan Allah dimana umat beriman mengambil bagian dalam hidup ilahi melalui sabda dan sakramen, dan pesekutuan dengan umat yang dibangun oleh semua anggota Gereja di dalam jemaat lokal (Samosir 2017, 26).

Jemaat lokal merujuk pada Gereja keuskupan yang terdiri dari gereja-gereja tingkap Paroki, dimana perkembangan komunitas basis berkembang dengan pesat. Komunitas gereja basis ini baik secara teritorial maupun secara kategorial. Salah satu persekutuan komunitas basis kategorial adalah kelompok kategorial anak-anak atau yang lebih dikenal dengan istilah BIAK.

Istilah BIAK (Bina Iman Anak Katolik) adalah salah satu istilah yang dipakai dalam katekese anak. BIAK diadakan supaya anak mengalami dan merasakan perjumpaan dan sapaan kasih Yesus sejak dini. Oleh karena itu kegiatan BIAK sangatlah penting dalam pengembangan iman anak usia dini di dalam Gereja lokal.

Kehadiran para mahasiswa STP- IPI Malang IPI malang prodi Pelayanan pastoral dalam kegiatan weekend pastoral, sangatlah memberi warna dalam kehidupan menggereja umat paroki Santo Vincentius a Paulo. Mereka terlibat di dalam kegiatan-kegiatan kelompok umat basis di lingkungan-lingkungan dalam paroki ini. Kegiatan weekend pastoral adalah suatu kegiatan yang dijalankan oleh mahasiswa STP-IPI Malang pada setiap hari Sabtu sore sampai dengan Minggu siang. Di dalam kegiatan weekend pastoral, mahasiswa terjun langsung di tengah umat beriman, dan bersama-sama dengan umat, membangun dan mewujudkan suatu komunitas Kristiani, suatu lingkungan/keluarga yang hidup, agar melalui hal ini Kristus dihadirkan ditengah-tengah keluarga/masyarakat.(Pedoman weekend pastoral STP- IPI 2016).

Dalam kegiatan weekend pastoral, ada banyak kegiatan yang dilakukan oleh mahasiswa, diantaranya orientasi pastoral (dengan metodik pekerjaan pastoral), kegiatan liturgi dan kegiatan pewartaan. Mereka juga diharapkan terlibat dalam kelompok-kelompok kategorial yang ada di dalam lingkungan/paroki. Permasalahan yang akan dijawab dalam penelitian ini adalah: bagaimana peran petugas weekend pastoral dalam kelompok kategorial BIAK, yang berkaitan dengan pelaksanaan Bina Iman Anak Katolik di paroki santo Vincentius a Paulo Malang.

Tujuan yang hendak dicapai dalam penelitian ini adalah: untuk mengetahui peranan petugas weekend pastoral dalam pelaksanaan katekese Bina Iman Anak Katolik (BIAK) di paroki santo Vincentius a Paulo Malang. Itu hanya merupakan salah satu kegiatan saja, dari sekian banyak peran yang Dalam kenyataannya peranan petugas weekend pastoral mencakup banyak kegiatan, terkait dengan orientasi pastoral, kegiatan liturgi, kegiatan katekese dan kegiatan lain yang berkaitan dengan hidup beriman.

\section{METODE PENELITIAN}

Metode yang gunakan dalam penelitian ini adalah kualitatif deskriptif. Menurut Bogdan dan Taylor (1992) menjelaskan bahwa penelitian kualitatif adalah salah satu prosedur penelitian yang menghasilkan data deskriptif berupa ucapan atau tulisan dan perilaku orang-orang yang 
diamati. Pendekatan kualitatif diharapkan mampu menghasilkan uraian yang mendalam tentang ucapan, tulisan, dan atau perilaku yang dapat diamati dari suatu individu, kelompok, masyarakat, dan atau organisasi tertentu dalam suatu keadaan konteks tertentu yang dikaji dari sudut pandang yang utuh, komperhensif, dan holistik.

Dalam penelitian ini, penulis mengambil rancangan studi kasus. Studi kasus merupakan penelitian mengenai manusia (dapat suatu kelompok, organisasi maupun individual), peristiwa, latar secara mendalam, tujuannya untuk mendapatkan gambaran yang mendalam tentang suatu kasus yang sedang diteliti. Pengumpulan data diperoleh dari wawancara dan observasi. Studi kasus yang dimaksudkan dalam penelitian ini terutama realisasi pelaksanaan katekese Bina Iman Anak Katolik (BIAK) di paroki St Vinsentius A Paulo Malang yang dilaksanakan oleh petugas weekend pastoral mahasiswa STP IPI Prodi pelayanan pastoral. Dalam konteks ini, penulis akan mengumpulkan informasi-informasi secara lengkap berkenaan dengan pelaksanaan kegiatan tersebut.

Penelitian ini diadakan di 9 lingkungan dari 13 lingkungan yang ada di paroki st. Vincentius a Paulo Malang. Hal ini dikarenakan hanya 9 lingkungan ini, yang menerima petugas weekend pastoral mahasiswa STP- IPI Malang prodi Pelayanan Pastoral. Kesembilan lingkungan tersebut sebagai berikut: Lingkungan santo Yohanes Pemandi, Lingkungan santa Cicilia, Lingkungan santo Bernardus, Lingkungan santo Carolus, Lingkungan santo Andreas, Lingkungan santa Maria, Lingkungan santo Petrus, Lingkungan santo Agustinus, Lingkungan santo Fransiskus Xaverius

Yang menjadi informan dalam penelitian ini adalah ketua lingkungan, pembina BIAK dan petugas weekend pastoral dimana petugas weekend pastoral menjalankan kegiatannya. Untuk memudahkan pengolahan datanya, peneliti menggunakan sistem koding sebagai berikut:

\begin{tabular}{|c|c|c|c|}
\hline No. & Nama Lingkungan & Status & Kode \\
\hline 1 & \multirow[t]{3}{*}{ Lingkungan St. Yohanes Pemandi } & Ketua lingkungan & A01 \\
\hline 2 & & Pembina BIAK & B01 \\
\hline 3 & & Petugas weekend & $\mathrm{C} 01$ \\
\hline 4 & \multirow[t]{3}{*}{ Lingkungan St. Cicilia } & Ketua lingkungan & $\mathrm{A} 02$ \\
\hline 5 & & Pembina BIAK & B02 \\
\hline 6 & & Petugas weekend & $\mathrm{C02}$ \\
\hline 7 & \multirow[t]{3}{*}{ Lingkungan St. Bernardus } & Ketua lingkungan & $\mathrm{A} 03$ \\
\hline 8 & & Pembina BIAK & B03 \\
\hline 9 & & Petugas weekend & $\mathrm{C} 03$ \\
\hline 10 & \multirow[t]{3}{*}{ Lingkungan St. Carolus } & Ketua lingkungan & A04 \\
\hline 11 & & Pembina BIAK & B04 \\
\hline 12 & & Petugas weekend & $\mathrm{C} 04$ \\
\hline 13 & \multirow[t]{3}{*}{ Lingkungan St. Andreas } & Ketua lingkungan & A05 \\
\hline 14 & & Pembina BIAK & B05 \\
\hline 15 & & Petugas weekend & $\mathrm{C} 05$ \\
\hline 16 & \multirow[t]{3}{*}{ Lingkungan St. Maria } & Ketua lingkungan & A06 \\
\hline 17 & & Pembina BIAK & B06 \\
\hline 18 & & Petugas weekend & $\mathrm{C06}$ \\
\hline 19 & \multirow[t]{3}{*}{ Lingkungan St. Petrus } & Ketua lingkungan & A07 \\
\hline 20 & & Pembina BIAK & B07 \\
\hline 21 & & Petugas weekend & $\mathrm{C07}$ \\
\hline
\end{tabular}




\begin{tabular}{|c|c|c|c|}
\hline 22 & \multirow[t]{3}{*}{ Lingkungan St. Agustinus } & Ketua lingkungan & A08 \\
\hline 23 & & Pembina BIAK & B08 \\
\hline 24 & & Petugas weekend & $\mathrm{C} 08$ \\
\hline 25 & \multirow[t]{3}{*}{ Lingkungan St. Fransiskus Xaverius } & Ketua lingkungan & A09 \\
\hline 26 & & Pembina BIAK & B09 \\
\hline 27 & & Petugas weekend & C09 \\
\hline
\end{tabular}

Tehnik pengumpulan data yag dipakai dalam penelitian ini adalah wawancara dan observasi. Menggunakan tehnik wawancara terarah (guided interview) di mana peneliti menggunakan pertanyaan-pertanyaan yang disiapkan sebelumnya. Pewawancara terikat dengan pertanyaan yang disiapkan sebelumnya (Sujarweni Wiratna 2014, 19).

Prosedur wawancara yang dipakai dalam penelitian ini adalah wawancara terstruktur. Peneliti menyiapkan pertanyaan terbuka sebelum melakukan wawancara. Pertanyaan-pertanyaan yang berkaitan langsung dengan keterlibatan atau peran petugas weekend pastoral dalam pelaksanaan Bina Iman anak katolik adalah sebagai berikut: Kelompok kategorial apa yang ada dalam lingkungan ? Peran apa yang dilakukan oleh petugas weekend pastoral, berkaitan dengan kelompok BIAK? Pertanyaan-pertanyaan tersebut ditanyakan kepada ketiga kelompok informan yang telah disebutkan diatas yaitu ketua lingkungan, pembina BIAK dan juga petuas weekend pastoral.

Untuk tehnik pengumpulan data dengan observasi, menggunakan observasi non partisipan yaitu pengamatan dimana peneliti tidak berperan serta. Pada pengamatan tanpa peran serta, pengamatan hanya melakukan satu fungsi yaitu mengadakan pengamatan terhadap aktivtasaktivitas yang terjadi selama kegiatan weekend dijalankan.

Hasil wawancara (transkrip) akan dikumpulkan, dan kemudian dipilah-pilah berdasarkan tema yang muncul dalam jawaban/data yang diperoleh. Lebih lanjut data-data yang telah dipahami tersebut, dimasukkan ke dalam kode-kode yang telah dibuat sebelumnya. Berdasarkan kode-kode yang didapat tersebut, data kemudian dideskripsikan dan diinterpretasikan untuk mendapatkan hasil. Sementara itu data hasil observasi dijadikan bahan untuk validasi data wawancara yang telah diproses agar kesimpulan yang didapat, bisa dipertanggungjawabkan.

\section{HASIL DAN PEMBAHASAN}

Bina Iman Anak Katolik (BIAK), biasa disebut juga dengan istilah Minggu Gembira atau Katekese anak.Ada banyak istilah untuk katekese anak antara lain: Sekolah Minggu, Minggu Gembira, Bina Iman Usia Dini (BIUD), Pendampingan Iman Anak (PIA) dan Sekolah Bina Iman (SBI). Namun yang dimaksud adalah satu yaitu pembinaan iman anak-anak Katolik (sampai usia menerima Komuni) dalam suasana gembira dan ceria (Bagiyowinadi Didik 2009, 29). Kegiatan ini didasarkan pada injil Mrk 10:13-16:

"Lalu orang membawa anak-anak kecil kepada Yesus, supaya ia menjamah mereka; akan tetapi murid-muridNya memarahi orang-orang itu. Ketika Yesus melihat hal itu, Ia marah dan berkata kepada mereka: "Biarkanlah anak-anak itu datang kepadaKU, jangan menghalang-halangi mereka; sebab orang-orang seperti itulah yang empunya Kerajaan Allah. Aku berkata kepadamu: Sesungguhnya barangsiapa tidak menyambut Kerajaan Allah seperti seorang anak kecil, ia tidak akan masuk ke dalamnya." Lalu Ia memeluk anak-anak itu dan sambil meletakkan tanganNya atas mereka, Ia memberkati mereka."

Kisah tersebut menunjukkan kasih dan perhatian Yesus pada anak-anak. Dari sebab itu, diperlukan orang dewasa yang mau membawa dan mengantar anak-anak untuk bisa datang dan bertemu 
dengan Yesus,supaya Ia menjamah dan memberkati mereka. Maka sangat pentinglah jika Gereja untuk memperhatikan kelompok kategorial BIAK ini, agar anak-anak dapat mengalami sapaan dan kasih dari Tuhan Yesus.

Dalam amanat terakhir, sebelum terangkat ke Surga, Yesus berpesan kepada para muridNya untuk menjadikan semua bangsa muridNya, dan mengajar mereka melakukan semua yang telah diperintahkan oleh Yesus (Bdk Mat 28:19-20). Mendasarkan diri pada teks tersebut, pengajaran iman/katekese adalah menjadi tugas utama dari Gereja. Tugas pengajaran iman/katekese ini, termasuk di dalamnya untuk kelompok katekese anak/Bina Iman anak Katolik (BIAK).

Pelaksanaan Bina Iman Anak Katolik/katekese anak untuk tiap paroki, ada beberapa macam, sesuai dengan kebijakan pastor paroki, yang didukung oleh bidang pewartaan. 1) BIAK dilaksanakan bersamaan saat perayaan ekaristi. Anak-anak yang belum menerima komuni, dikumpulkan di ruangan yang berbeda, diberi pembinaan iman oleh seorang atau beberapa orang pembina. Setelah komuni, anak-anak diajak masuk ke gereja secara berurutan untuk menerima berkat dari pastor/imam. Hal ini dilakukan untuk mengurangi keributan anak-anak saat perayaan ekaristi kudus. 2) BIAK diadakan sesudah atau sebelum perayaan ekaristi. Pada saat perayaan ekaristi, anak-anak mengikuti perayaan ekaristi bersama orang tua mereka. 3) BIAK diadakan di tiap lingkungan. jika lingkungan terlalu sedikit jumlah anak BIAK nya, maka lingkungan itu akan bergabung dengan lingkungan lain. Kegiatan BIAK diadakan secara bergilir di rumah umat.

Pelaksanaan pembinaan iman anak katolik di dalam paroki, memang tergantung dari kebijakan setempat. Namun yang lebih utama adalah bahwa pembinaan iman anak, tidak boleh ditinggalkan. Karena anak-anak adalah masa dengan Gereja. Di tangan merekalah perkembangan Gereja yang akan datang ditentukan.

\section{Kegiatan weekend pastoral}

Pelaksanaan kegiatan weekend pastoral mahasiswa STP- IPI Malang, telah diatur sesuai dengan pedoman pelaksanaan yang telah berlaku di dalam lembaga ini. Weekend pastoral adalah suatu kegiatan yang dijalankan oleh Mahasiswa STP-IPI Malang pada setiap hari Sabtu sore sampai dengan Minggu siang. Di dalam Weekend pastoral, mahasiswa terjun langsung di tengah umat beriman. Dan bersama-sama dengan umat membangun dan mewujudkan suatu komunitas kristiani, suatu lingkungan/keluarga yang hidup, agar melalui hal ini Kristus dihadirkan di tengahtengah keluarga/masyarakat.

Weekend pastoral adalah salah satu wujud pengabdian masyarakat dari STP-IPI Malang program studi pelayanan pastoral. Kegiatan Weekend Pastoral bertujuan: 1) Mulai menerapkan pengetahuan dan keterampilan yang diterimanya ini di bangku kuliah dalam situasi konkrit umat; 2) Mengembangkan semangat merasul dan kepedulian mahasiswa STP-IPI terhadap situasi umat; 3) Memberi kesempatan kepada mahasiswa untuk mengolah pengalaman nyata umat dari apa yang dihadapinya; 4) Memberi motivasi dan dukungan kepada umat dalam pelaksanaan pekerjaanpekerjaan pastoral untuk melakukan kegiatan yang sesuai dengan kemampuan mereka; 5)Membantu menyelesaikan bersama tugas-tugas Pastoral pengurus lingkungan/stasi; 6) Turut serta mewujudkan suatu persekutuan hidup kristiani yang diterangi injil yang mampu menghadirkan Kristus di masyarakat dalam situasi konkrit.

Kegiatan weekend pastoral dilakukan oleh mahasiswa STP-IPI Program Studi Pelayanan Pastoral selama tiga semester yaitu: semester II (di wisma anak berkebutuhan khusus), semester III dan semester IV (di paroki). Untuk semester gasal dimulai bulan Agustus sampai dengan akhir Desember. Sedangkan untuk semester genap, dimulai bulan Januari sampai Mei. Waktu yang 
disedikan untuk menjalankan Weekend pastoral adalah mulai Sabtu sore ( $\pm 16.00 \mathrm{WIB})$ sampai dengan Minggu siang (13.00 WIB). Tidak tertutup kemungkinan adanya kegiatan lingkungan/Paroki yang terjadi di luar waktu tersebut. Mahasiswa diperkenankan untuk menghadiri/terlibat di dalamnya sejauh tidak mengganggu kehadiran dan keterlibatannya dalam kegiatan-kegiatan perkuliahan STP-IPI. Selama menjalankan Weekend Pastoral, mahasiswa diperkenankan menginap di rumah umat dan mengikuti kegiatan umat di akhir pekan.

Mahasiswa yang melakukan kegiatan weekend pastoral di paroki adalah mahasiswa semester III dan IV, yang telah memiliki sejumlah pengetahuan dan keterampilan dasar yang perlukan untuk pelaksanaan pekerjaan Pastoral. Dalam kegiatan ini, mereka terjun langsung ke tengah-tengah umat yaitu di paroki, stasi atau lingkungan, guna mengaplikasikan pengetahuan dan ketrampilan pastoral. Mereka diharapkan menjadi pekerja pastoral bersama dengan pengurus lingkungan/stasi setempat, mampu membentuk persekutuan hidup yang diterangi oleh Injil, mampu mewujudkan kabar gembira dalam situasi nyata.

Beberapa pokok kegiatan yang dilakukan saat menjalankan weekend pastoral adalah, pertama-tama seorang petugas weekend pastoral harus melakukan legitimasi kepada pastor paroki, ketua DPP dan ketua-ketua lingkungan, dimana mereka diutus. Setelah mendapatkan ijin dari pastor paroki dan ketua DPP, barulah mereka mengadakan legitimasi ke lingkungan-lingkungan dimana mereka diutus. Di dalam lingkungan inilah, mereka dijelaskan hal-hal yang berkaitan dengan hidup iman umat lingkungan yang dilayani.

Setelah mendapatkan ijin dari ketua lingkungan, barulah petugas mulai terlibat aktif dalam kegiatan yang ada dalam lingkungan, sesuai dengan arahan dan petunjuk dari ketua lingkungan. Kegiatan-kegiatan tersebut berdasarkan dalam pedoman pelaksanaan weekend pastoral yaitu: 1) Orientasi pastoral menggunakan metodik pekerjaan pastoral, yang terdiri dari tujuh (7) langkah yaitu mulai dari perkenalan pastoral, inventarisasi/sensus, bimbingan, musyawarah pastoral, penyusunan program, pelaksanaan program dan evaluasi. 2) Terlibat aktif dalam kegiatan liturgi, kegiatan pewartaan berdasarkan kelompok kategorialnya. 3) mengikuti kegiatan lain yang menunjang karya pastoral di lingkungan/paroki tersebut. Sebelum menjalankan kegiatan, petugas weekend membuat persiapan, dan sesudah menjalankan kegiatan, mereka membuat laporan termasuk di presensi.

Kerjasama antara prodi Pelayanan Pastoral STP- IPI Malang dan paroki St. Vincentius a Paulo Malang dalam hal pelaksanaan kegiatan weekend pastoral, sudah terjalin cukup lama. Durasi waktu ini mau mengatakan, bukan sekedar tentang kebiasaan atau lamanya kerjasama yang terjalin, melainkan juga produk-produk keterlibatan mahasiswa bagi perkembangan komunitas basis, secara khusus dalam hal pembinaan iman anak usia dini atau BIAK. Eksplorasi ini penting bagi institusi dalam proses pembelajaran dan pendidikan bagi calon pekerja pastoral dalam Gereja di masa yang akan datang. Institusi akan memperoleh apresiasi dan juga masukan-masukan yang perlu, berkaitan dengan hal-hal seputar peran petugas weekend pastoral dalam kegiatan BIAK di paroki ini.

Dalam pelaksanaan kegiatan weekend pastoral oleh mahasiswa STP- IPI Malang prodi pelayanan Pastoral, mahasiswa dilibatkan lansung dengan berbagai kegiatan yang ada dalam lingkungan, sesuai dengan arahan dari ketua lingkungan. Hasil dari wawancara dengan ketua lingkungan, pembina BIAK dan petugas weekend pastoral diperoleh hasil bahwa dari sembilan lingkungan di mana petugas weekend pastoral menjalankan tugas; 1 lingkungan memiliki kelompok BIAK saja, 2 lingkungan memiliki kelompok BIAK dan REMAKA, 5 lingkungan memiliki kelompok BIAK, REMAKA, dan OMK, dan 1 lingkungan tidak memiliki kelompok kategorial usia muda (BIAK, REMAKA, OMK). 
Dari ketiga kelompok kategorial usia muda yang ada di lingkungan-lingkungan, kelompok BIAK yang paling dominan didampingi oleh petugas Weekend. karena pada dasarnya petugas weekend datang ke lingkungan membawa serta persiapan pembinaan untuk BIAK, dan keterlibatan dalam kelompok REMAKA petugas weekend hanya sebagai peserta, dan mereka tidak terlibat dalam kelompok OMK. Kegiatan kelompok REMAKA lebih terfokus pada kegiatan di paroki, sedangkan kelompok OMK hampir tidak ada kegiatan di lingkungan dengan alasan berbagai kegiatan di sekolah maupun tuntutan pekerjaan. Dari kelompok-kelompok kategorial yang ada di lingkungan, petugas weekend terlibat aktif dalam mendampingi kelompok BIAK pada kegiatan Minggu Gembira.

Pembina BIAK lingkungan mengungkapkan bahwa kelompok kategorial yang ada juga bervariasi. Tiga Koordinator BIAK lingkungan mengatakankan di lingkungan dimana dia tinggal terdapat kelompok BIAK, REMAKA, dan OMK, 2 lingkungan terdapat kelompok BIAK, REMAKA, dan 4 lingkungan hanya ada kelompok BIAK. Pesponden B07 mengatakan di lingkungannya terdapat 3 kelompok kategorial "Iya, ada: BIAK seminggu sekali, REMAKA seminggu sekali, OMK dua Minggu sekali atau jika ada even-even tertentu seperti latihan koor, kemah, rekoleksi tentang berpacaran, seksualitas.”. Lain pula dengan pernyataan responden B01 yang menyatakan "Per kategori itu ada Pembinaan BIAK, REMAKA, OMK. Tapi di antara ketiga itu yang OMK akhir-akhir ini tidak jalan karena kuliah, tuntutan sekolah, alasannya sibuk, yang kerja ndak mau bergabung".

Dari 3 kelompok kategorial yang ada, petugas Weekend selama ini terlibat aktif dalam menjalankan pendampingan BIAK. Diakui oleh para ketua lingkungan dan pembina BIAK lingkungan bahwa lingkungan sangat terbantu terutama dalam pendampingan BIAK. Para petugas weekend yang masih muda dibandingkan dengan pembina BIAK lingkungan mempunyai kreasi lebih dalam menciptakan gerak dan lagu maupun dalam aktifitas lain. Beberapa pembina mengatakan mereka masih energik dan lincah dalam menciptakan gerakan-gerakan kreasi terbaru. Tugas yang sering diemban oleh seorang petugas Weekend pastoral pada saat ke lingkungan adalah pendampingan BIAK, yang bertujuan untuk mendidik anak-anak, memberikan pengetahuan tentang pendidikan agama Katolik, melatih keberanian dan kepercayaan diri.

Berdasarkan wawancara dengan ketua lingkungan diperoleh data bahwa dari 8 lingkungan mengatakan petugas Weekend terlibat aktif dalam kegiatan Bina Iman Anak, dan satu lingkungan memang tidak ada kegiatan BIAK. Namun hasil dari wawancara dengan petugas weekend pastoral (C09), mereka mendampingi atau melakukan pembinaan iman anak yang diadakan di paroki, yaitu kelompok BIAK dari lingkungan-lingkungan yang tidak ada kelompok BIAK (ada 5 lingkungan) dan juga anak-anak yang bersama orangtua mengikuti perayaan ekaristi di hari Minggu Pukul 08.00 wib.

Setiap petugas Weekend pastoral yang datang ke lingkungan membawa persiapan materi dan aktivitas dalam pembinaan. Materi-materi tersebut dibuat sesuai dengan tema tahun liturgi pada saat mereka melaksanakan tugas. Materi yang dipersiapkan diharapkan menarik agar anak merasa senang dan pesan yang disampaikan bisa diterima oleh anak dengan baik pula, seperti yang diharapkan oleh responden A01"yang mendasar sekali yaitu BIAK harus menguasai materi supaya nanti anak-anak itu bisa menarik karena pengalaman-pengalaman di lingkungan itu tidak semua anak yang bisa membawa anak itu bisa menarik, selama ini ya itu tadi selama ini berapa bulan ya, satu tahun, ada yang justru menarik itu anak yang mempunyai bakat a menari, kemudian menyanyi, kadang-kadang selama ini kurang pintar menyanyi sehingga kadang-kadang suaranya yang mau ajarkan kepada BIAK kurang menguasai, dituntun punya ketrampilan supaya menarik." Di samping membeikan materi, petugas Weekend Pastoral memberikan kegiatan berupa latihan 
menari. Hal ini dilakukan dalam rangka mempersiapkan jika ada tugas dalam perayaan misa besar. Kegiatan Weekend dilaksanakan dalam rangka praktik mahasiswa

Hasil wawancara dengan Pembina BIAK lingkungan, menyatakan bahwa petugas Weekend Pastoral aktif dalam kegiatan BIAK di lingkungan. Koordinasi dengan Pembina lingkungan terjalin dengan baik, seperti yang diungkapkan oleh responden A03 'Komunikasi aktif, jadi setiap kali mereka datang dia itu mesti ke rumah saya, jadi ke koordinasi apa yang akan dilaksanakan hari ini, apa yang di..., kalau mungkin ke BIAK, apa yang diajarkan hari ini, contohnya hari ini akan saya ajari menggambar. Nah, kami kan otomatis menyediakan pensil, dan sebagainya'.

Pendampingan BIAK merupakan salah satu bagian dari bidang pewartaan yang terdapat pada Pokok-pokok Weekend Pastoral. Di dalam pendampingan bahan telah disediakan oleh lembaga STP-IPI Malang, akan tetapi tidak menutup kemungkinan bahwa petugas mencari sumber bahan lain yang selaras dengan tema yang bersangkutan. Pendampingan bertujuan untuk membina iman anak untuk lebih mengenal Tuhan Yesus. Pendampingan BIAK sangat membantu lingkungan-lingkungan, paroki dalam usaha mendapatkan rekan kerja dalam pendampingan anak BIAK bersama pembina di lingkungan.

\section{KESIMPULAN}

Dari hasil penelitian yang telah dilakukan dari ketiga kelompok informan, dapat disimpulkan bahwa dari sembilan lingkungan hampir semua lingkungan memiliki kelompok kategori BIAK; hanya beberapa lingkungan saja yang memiliki kelompok kategori REMAKA dan OMK, dan satu lingkungan yang tidak memiliki kelompok kategori usia ini. Lingkungan yang tidak memiliki kelompok kategorial yang telah disebutkan tadi, dikarenakan mayoritas umat yang ada di lingkungan tersebut adalah usia orang dewasa dan lanjut usia.

Sementara itu peran dari petugas weekend pastoral dalam pendampingan kelompokkelompok kategorial berdasarkan usia sangat bervariasi. Hal ini tergantung dari keberadaan kelompok-kelompok tersebut di lingkungan. Semua petugas weekend pastoral mendampingi kelompok kategorial BIAK. Untuk petugas weekend yang di lingkungan tidak ada kelompok kategorial BIAK, mereka mendampingi kelompok kategorial BIAK yang ada di paroki. Diakui oleh para ketua lingkungan dan pembina BIAK lingkungan bahwa lingkungan sangat terbantu terutama dalam pendampingan BIAK. Para petugas weekend yang masih muda dibandingkan dengan pembina BIAK lingkungan mempunyai kreasi lebih dalam menciptakan gerak dan lagu maupun dalam aktifitas lain. Beberapa pembina mengatakan mereka masih energik dan lincah dalam menciptakan gerakan-gerakan kreasi terbaru.

Pelaksanaan pendampingan kelompok BIAK secara umum dijalankan dengan baik. Para petugas weekend pastoral biasanya sudah membawa persiapan dan bahan atau sarana/alat peraga yang akan digunakan pada waktu kegiatan BIAK berlangsung. Hal ini akan sangat mendukung, sehingga proses pelaksanaan pembinaan Iman Anak dapat berjalan dengan lancar dan menyenangkan. Selain itu materi-materi yang akan dibawakan, juga dikomunikasikan dengan baik bersama para pembina BIAK yang ada di lingkungan. Namun ada satu hal yang cukup disoroti dan perlu dikembangkan lebih lanjut adalah bahasa yang digunakan ketika menyampaikan materi kepada anak-anak, agar para petugas menggunakan bahasa yang lebih sederhana dan mudah dipahami anak-anak.

Dari hasil temuan-temuan yang berkaitan dengan kelompok kategorial BIAK, petugas weekend pastoral sudah sangat berperan aktif, bahkan pembina BIAK dilingkungan merasa sangat terbantu. Namun ada hal penting yang perlu diperhatikan yaitu bahwa kehadiran petugas weekend 
pastoral bukan untuk menggantikan tugas pembina BIAK di lingkungan. justru kehadiran mereka harus dapat menumbuhkan simbiosis mutualisme. Dari sisi pembina BIAK lingkungan, merasa terbantu dalam mendampingi anak-anak BIAK dan saling berbagi dalam hal pengayaan lagu-lagu baru dan kreasi yang baru. Dan dari sisi petugas weekend pastoral dapat belajar mengelola kelompok BIAK yang sesungguhnya dan juga tehnik-tehnik pendekatan kepada anak-anak.

Tulisan ini didasarkan dari hasil penelitian dengan judul "Efektifita kegiatan weekend pastoral mahasiswa di lingkungan-lingkungan paroki santo Vincentius a Paulo Malang." Namun dalam tulisan ini lebih menyoroti peran dari petugas weekend pastoral dalam pendampingan kelompok kategorial BIAK, yang merupakan salah satu sup tema yang ada dalam penelitian tersebut. Penelitian ini dilakukan sebagai evaluasi terhadap kegiatan weekend pastoral yang sudah berjalan cukup lama. Hasil dari penelitian ini akan digunakan sebagai masukan bagi program studi pelayanan Pastoral dalam kaitannya dengan mempersiapkan bekal bagi mahasiswa yang akan menjalankan kegiatan weekend pastoral dan juga upaya meningkatkan kualitas pengabdian kepada masyarakat secara khusus dalam paroki tempat dimana mahasiswa melakukan kegiatan weekend.

\section{DAFTAR PUSTAKA}

Ardhisubagyo, Y. 1987. Menggereja di Kota. Seri Pastoral 136.

Bagiyowinadi, FX. 2009. Bekal untuk Pendamping Bina Iman Anak. Yogyakarta: Pustaka Nusantara.

Dirjen Bimas Katolik Depag RI. 2020. Komunitas Basis Kristiani. Jakarta: Departemen Agama. Dirjen Bimas Katolik Depag RI. 2001. Membina Persaudaraan Sejati. Jakarta: Departemen Agama.

Firmanto, Antonius. 2004. Pengelolaan dan Pemberdayaan Jemaat. Malang: Dioma.

Hardawiryana, R. (Penerj). 1993. Dokumen Konsili Vatikan II. Jakarta: Obor.

Komisi Kateketik KWI. 2000. Komunitas Basis Gerejawi. Jakarta: Komkat KWI.

Moleong, Lexy, J. 2012. Metode Penelitian Kualitatif. Bandung: PT. Remaja Rosdakarya.

Mudjijo, Paulus. 2011. Komunitas Basis Gerejawi. Malang: STP-IPI Malang.

Panitia Yubelium Keuskupan Malang. 2002. BUKU KENANGAN YUBELIUM 75 KEUSKUPAN MALANG. Malang: Tim Buku Kenangan.

Sarwono, Jonathan. 2013. Strategi Melakukan Riset. Yogyakarta: Penerbit Andi.

Slamet. 2010. Materi Kuliah Manajemen Kelompok dan Organisasi. Ceramah yang disampaikan pada mahasisa program S2 Prodi Ilmu Penyuluhan Pembangunan Sekolah Pascasarjana IPB

Soeprapto. 2011. Metode Penelitian Kualitatif. Jakarta: Universitas Terbuka.

Tim. 2016. Pedoman Weekend Pastoral. Malang: STP- IPI Malang Prodi Pelayanan Pastoral.

Suratman, Y. 1999. Membangun Komunitas Basis Gerejawi. Jakarta: Celesty Hieronika.

Tondowidjojo, John. 1989. Pastoral Paroki Masa Kini. Malang: Dioma.

Widharsana, Petrus Danan dan Hartono, Victorius Rudy. 2016. Pengajaran Iman Katolik. Yogyakarta: Kanisius.

Wadiyo, Berkesenian: Tindakan Sosial menurut Max Weber, Jurnal Seni Imajinasi, Vol. 3, No. 2, 2007.

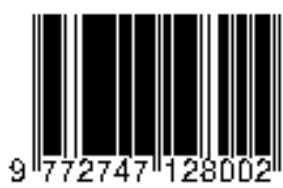

